\title{
RESEARCH
}

\section{The Region Surrounding The PKD1 Gene: A 700-kb P1 Contig from a YAC-deficient Interval}

\author{
William R. Dackowski, ${ }^{1}$ Timothy D. Connors, ${ }^{1}$ Ann E. Bowe, ${ }^{1}$ \\ Vincent Stanton Jr., ${ }^{2}$ David Housman, ${ }^{2}$ Norman A. Doggett, ${ }^{3}$ \\ Gregory M. Landes, ${ }^{1,4}$ and Katherine W. Klinger ${ }^{1}$
}

\author{
${ }^{1}$ Department of Human Genetics, Integrated Genetics, Framingham, Massachusetts $01701 ;{ }^{2}$ Center for \\ Cancer Research, Massachusetts Institute of Technology, Cambridge, Massachusetts 02142; ${ }^{3}$ Life \\ Sciences Division and Center for Human Genome Studies, Los Alamos National Laboratory, \\ Los Alamos, New Mexico 87545
}

\begin{abstract}
As part of an effort to identify the gene responsible for the predominant form of polycystic kidney disease (PKDI), we used a gridded human P1 library for contig assembly. The interval of interest, a 700-kb segment on chromosome 16pl3.3, can be physically delineated by the genetic markers D16S125 and D16S84 and chromosomally characterized as a GC-rich isochore enriched for $\mathrm{CpG}$ islands, genes, and Alu-like repeats. Our attempts to recover CEPH YACs that encode this region of chromosome 16 were unsuccessful. However, we screened an arrayed P1 library using 15 distinct probes from the D16S125-D16S84 interval and identified 56 independent $\mathrm{Pl}$ clones. Only one probe from the interval was unsuccessful in identifying a $\mathrm{Pl}$ clone. Forty-four Pl clones were determined to be unique based on restriction enzyme analysis, and 42 of these were found to originate from chromosome 16pl3.3, based on FISH to metaphase chromosomes. The 700-kb interval could be defined by a single sequence-ready contig comprised of $12 \mathrm{PI}$ clones and 1 cosmid clone. Our studies support the use of multiple libraries to generate the requisite physical reagents for positional cloning and encourage the use of Escherichia coli-based large-insert cloning systems to recover clones from YAC-deficient chromosomal intervals.
\end{abstract}

The assembly of contiguous cloned genomic reagents is a necessary step in the process of disease-gene identification using a positional cloning approach. The rapid development of highdensity genetic maps based on polymorphic simple sequence repeats has facilitated contig assembly using sequence-tagged site (STS) content mapping. Most contig construction efforts have relied on yeast artificial chromosomes (YACs), because their large insert size uses the current STS map density more advantageously than bacterially hosted systems. This approach has been validated for multiple human chromosomes with YAC coverage ranging from $65 \%-95 \%$ for many chromosomes and contigs of $11-36 \mathrm{Mb}$ being described (Chumakov et al. 1995; Doggett et al. 1995; Gemmill et al. 1995; Krauter et al. 1995; Shimizu et al. 1995; van-Heyningen et al. 1995).

${ }^{4}$ Corresponding author.

E-MAIL glandes@world.std.com; FAX (508) 620-1203.
Even with numerous successes, the YAC cloning system is not a panacea for cloning the entire genome of complex organisms because of intrinsic limitations that result in substantial proportions of chimeric clones (Green et al. 1991; Bellanne-Chantelot et al. 1992; Nagaraja et al. 1994), as well as clones that are rearranged, deleted, or unstable (Neil et al. 1990; Wada et al. 1990; Zuo et al. 1992; Szepetowski et al. 1995). At least some of these cloned artifacts are a product of the recombinational machinery of yeast acting on the various types of repetitive elements in mammalian DNA (Neil et al. 1990; Green et al. 1991; Schlessinger et al. 1991; Ling et al. 1993; Kouprina et al. 1994; Larionov et al. 1994). Alternative cloning systems must be used in concert with YAC-based approaches to complement localized YAC cloning deficiencies, to enhance the resolution of the physical map, and to provide a sequence-ready resource for genome-wide DNA sequencing. 


\section{DACKOWSKI EI AL.}

To meet this demand, several Escherichia colibased cloning systems have been developed using vectors based on P1 phage (Sternberg 1990) and F-factor, termed bacterial artificial chromosomes or BACs (Shizuya et al. 1992). In each case, these cloning systems permit larger average insert size when compared with traditional genomic approaches using $\lambda$ phage replacement vectors (15-22 kb) and cosmid vectors (30-45 kb). For example, the "head-full" packaging mechanism of P1 phage has been used to generate a threegenome equivalent human library with an average insert size of $-80 \mathrm{~kb}$ (Shepherd et al. 1994). The F-factor system has achieved even larger insert sizes. Using electroporation to introduce the products of ligation into $E$. coli allows generation of clones $\leqslant 300 \mathrm{~kb}$ (Shizuya et al. 1992). Similar results have been reported using the pCyPAC vector, a modified P1 phage vector, which selects for clones with inserts by inactivation of SacBII activity and relies on electroporation rather than transduction for introduction into bacteria (Ioannou et al. 1994).

Whereas clones with large inserts are beneficial, clone integrity and stability are paramount in generating an accurate high-resolution physical map and as a resource for genome-wide sequencing. Preliminary data suggest that of all large insert cloning vectors, these requirements have been satisfied most completely by both the P1- and F-factor-based genomic cloning systems. Their physical stability does not depend solely on insert size, as inserts of $\mathrm{P} 1$ recombinants (P1s) and F-factor recombinants (BACs) are intermediate to those from cosmids and YACs. This feature must be attributable in part to genes encoded by P1 and F-factor vectors that regulate and maintain one to two episomal copies per cell. Cosmidderived inserts were shown to be more stably maintained in F-factor based vectors than cosmid vectors (Kim et al. 1992).

As part of an effort to identify the gene responsible for the predominant form of polycystic kidney disease (PKD1), we evaluated several human libraries for contig assembly including a P1 library. This 700-kb chromosomal segment serves as a challenging test for large-insert cloning systems in $E$. coli and yeast because it resides in a GC-rich isochore (Saccone et al. 1992) with an abundance of CPG islands (Harris et al. 1990; Germino et al. 1992), genes (Germino et al. 1993), and Alu repetitive sequences (Korenberg et al. 1988). Chromosome 16 also contains more low-copy repeats than other chromosomes with almost $25 \%$ of its cosmid contigs hybridizing to more than one chromosomal location when analyzed by fluorescence in situ hybridization (FISH) (Okumura et al. 1994). These low-abundance repeats, several of which reside in the interval described in this paper, present a challenge to hybridization-based methods of contig construction because they are not blocked by preannealing with Cot1 DNA. Furthermore, lowcopy repeats may lead to instability of this interval in bacteria, yeast, and higher eukaryotes. Consistent with this prediction is the finding that most cases of severe infantile PDK1 are attributable to chromosomal deletions of this interval that minimally eliminate both $P K D 1$ and the adjoining tuberous sclerosis type 2 (TSC2) gene (Brook-Carter et al. 1994).

We describe our experience using a gridded P1 library to clone a 700-kb interval on chromosome $16 \mathrm{p} 13.3$. This interval was not recovered from the Centre d'Etude du Polymorphisme Humain (CEPH) YAC library by STS content mapping (Mark I, Mark II, and Mega-YAC) or hybridization-based screening (Mark II and Mega-YAC). Our analysis of the P1 library and the resulting P1 clones includes library screening efficiency for both multiple probes and multiple rounds of chromosome walking, chimerism rate based on FISH and insert size determination.

\section{RESULTS}

As a first step in assembling a transcriptional map of the region around PKD1, we attempted to clone the interval by STS screening of the CEPH YAC library. Twelve of the 13 STSs used in the initial screening were derived from the $700-\mathrm{kb}$ region defined by the closest flanking proximal and distal disease markers at that time, D16S125 (26-6) and D16S84 (CMM65), respectively (Fig. 1). An additional STS, D16S276, was also included in the screening set and is located $\sim 250 \mathrm{~kb}$ telomeric of D16S84. The set of STSs used included nine genetic markers (D16S84, D16S125, D16S283，D16S291，D16S662，D16S663, D16S664, D16S665, and D16S3252), one gene (D16S666E), and STSs developed from cosmids 16-140N (D16S276), 302H7 (D16S1103), 325A11 (D16S139), and 16-198N (D16S280). Some putative positives were identified in both the Research Genetics and Los Alamos National Labratory (LANL) primary CEPH pools, but none of these resulted in the identification of individual YACs encoding the desired STS. Following the 
A 700-KB PI CONIIG CONIAINING THE PKDI GENE

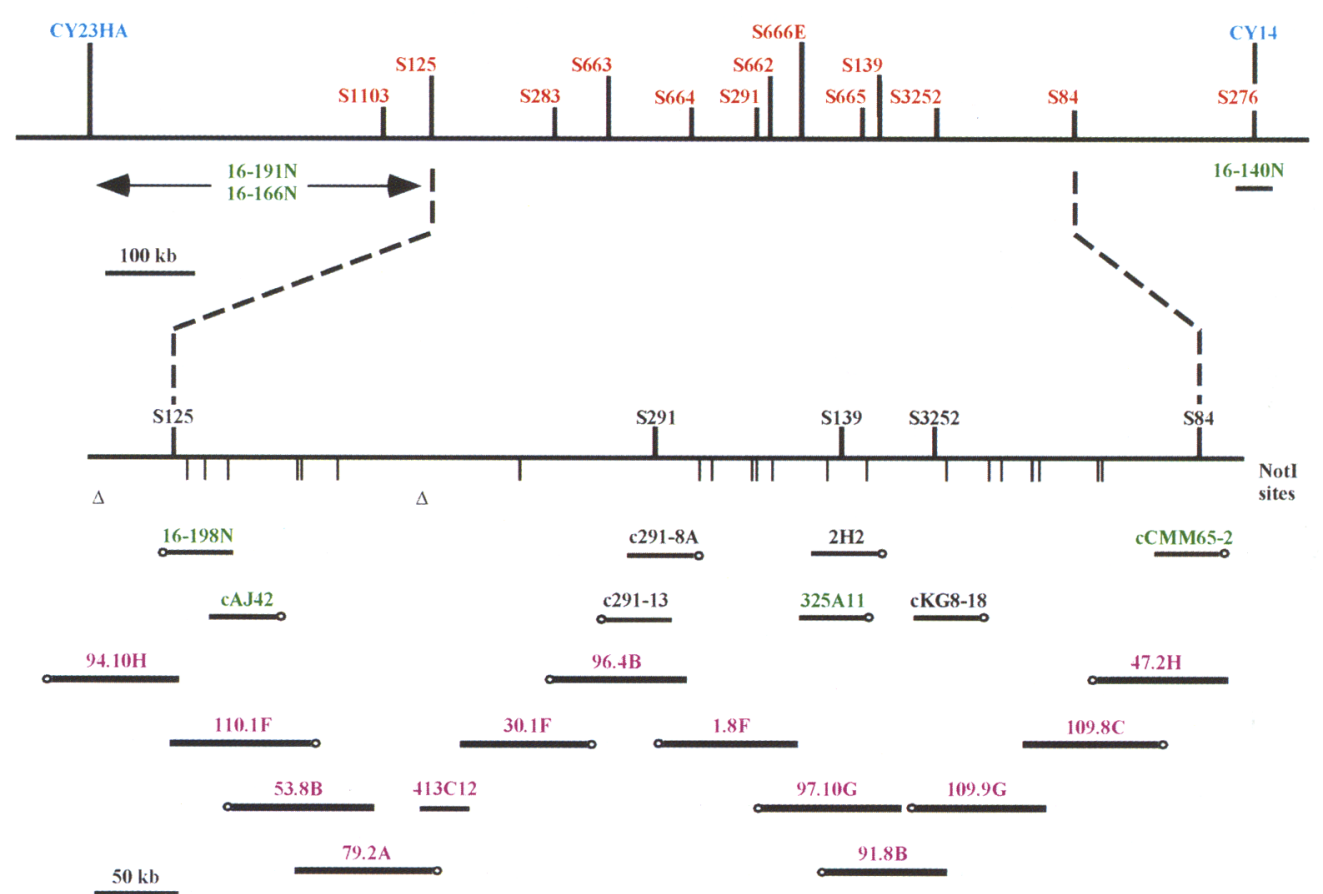

Figure 1 STS and clone resources used for genomic library screening. The upper portion displays an $\sim 1.5-\mathrm{Mb}$ genomic interval on chromosome 16p13.3 defined by the respective breakpoints within the hybrids $\mathrm{CY} 23 \mathrm{HA}$ and CY14 (blue). An expanded view of a 700-kb segment of this map is presented in the middle portion. DNA markers are listed above both horizontal map lines. The closest flanking genetic markers at the time of library screening were D16S125 (proximal) and D16S84 (distal). Individual cosmids and their locations are depicted immediately below each horizontal map line. DNA markers used for STS-based screening of the CEPH YAC library are shown in red in the upper portion. Cosmid-derived IRS products used to screen IRS products from the CEPH YAC pools are displayed in green. In the expanded map view (middle), the Notl sites are shown as thin vertical bars below the map line. The same panel also shows the location of two gaps $(\triangle)$ in a previously described cosmid/phage contig of this interval (Germino et al. 1992). The lower portion lists the ordered minimum tiling set of walking clones (labeled in purple). The set is comprised of $12 \mathrm{P} 1$ clones and a single cosmid clone, 413C12. (O) The T7 end of each cosmid and P1 clone.

discovery of the TSC2 gene (Chromosome $16 \mathrm{Tu}$ berous Sclerosis Consortium 1993) and the PKD1 gene (European Polycystic Kidney Consortium 1994), the LANL CEPH primary pools were unsuccessfully screened for the presence of these gene-specific STSs.

Subsequently, two different approaches were taken. First, interspersed-repetitive sequence (IRS) probes were generated by PCR using the previous set of cosmids and two additional cosmids, $16-166 \mathrm{~N}$ and $16-191 \mathrm{~N}$, as templates (Fig. 1). The cosmid-derived IRS probes were used to screen filter grids containing IRS products derived from the CEPH YAC library. The gridded DNA targets consisted of IRS products derived from complex pools of YAC clones (Liu et al. 1995). All YACderived products were present in duplicate on the filter grids to ensure hybridization specificity. From the Mark II and Mega-YAC libraries, six
YACs were identified that contained inter-Alu PCR products complementary to those from individual cosmids: 716H6, 723A1, 730C6, 731F2, $818 \mathrm{E} 9$, and $889 \mathrm{~A} 9$. Cosmids from two loci that flank PKD1 and are separated by $\sim 1 \mathrm{Mb}, A T P 6 C$ and D16S276, yielded inter-Alu products that were complementary to sequences present in the YAC 731F2. YAC sizing data available from CEPH indicated that two of the YACs, $730 \mathrm{C} 6(240 \mathrm{~kb})$ and $731 \mathrm{~F} 2(330 \mathrm{~kb})$, were too small to contain the entire PKD1 interval. Similar analyses using STS content mapping results (unambiguous and disambiguated hits only) for each of the YACs in question indicated chimerism for YACs $716 \mathrm{H} 6$, $723 \mathrm{~A} 1,731 \mathrm{~F} 2$, and 889A9. These data were confirmed by FISH analysis of metaphase chromosomes using biotinylated IRS products from the five largest YACs as probes, excluding 730C6. The FISH localizations showed the YACs to be either 


\section{DACKOWSKI ET AL.}

chimeric $(716 \mathrm{H} 6,723 \mathrm{~A} 1$, and $731 \mathrm{~F} 2)$, derived from a chromosome other than chromosome 16 $(818 \mathrm{E} 9,889 \mathrm{~A} 9)$ or to be derived from an interval proximal to chromosome $16 \mathrm{p} 13.3$ (716H6 and 731F2). A portion of clone $716 \mathrm{H} 6$ appeared to originate from chromosome $16 \mathrm{q}$, whereas clone $731 \mathrm{~F} 2$ localized to both the long (chromosome 16q23) and short arm (chromosome 16p13.1p13.2) of chromosome 16. These results, coupled with our success screening the gridded P1 library (see below), prompted us to abandon the chimeric YAC reagents at this stage.

We began to survey a gridded total human P1 library for homologous clones from the PKD1 region while the YAC library screening was in progress. The P1 library was chosen instead of the gridded chromosome 16 cosmid library for two reasons: First, the larger insert size of P1s (70-95 $\mathrm{kb})$ would minimize the number of walks required; and second, the low-copy number of P1s would enhance the stability of the genomic inserts relative to cosmids and YACs. The P1 library was comprised of $\sim 12,000$ pools of $10-12$ P1s per pool. The total complexity of the library was estimated to be $\sim 3$ genome equivalents (Shepherd et al. 1994). Initial chromosome walking was performed unidirectionally from the ends of the interval (ATP6C, D16S84) and bidirectionally from several internal loci (D16S291, D16S139, and D16S3252). With one exception, multiple probes were used simultaneously to screen the highdensity grids. As new walking clones were identified, they were assigned to developing contigs using multiple criteria (see below). Sets of unique, nonoverlapping ends of each new walking clone were used to rescreen the P1 filter grids. Walking probes, derived from the appropriate cosmid or P1 end, were of two types, labeled transcripts or bubble-PCR products (Riley et al. 1990).

Five screenings were performed using 15 probes (Table 1). One probe, $30.1 \mathrm{~F} \mathrm{T7}$, was used in two screenings. A total of 66 pools were positive, with an average of 4.1 positive pools per probe. The range of positive pools was two to eight pools per probe, with $80 \%$ of the independent screenings showing two to four positive pools per probe. Fifty-six clones ( $\sim 85 \%$ of the primary positives) were recovered after secondary screening; 44 clones were unique. On average, 3.5 P1s were recovered per probe, which is consistent with the complexity of the library. Fourteen of 15 probes were used successfully to recover P1 clones. None of the pools contained P1 clones complementary to the probe cKG8 T7.
However, this failure had little impact on the cloning of the interval (see below).

The chromosomal origin of all walking clones was determined by FISH to metaphase chromosomes. Forty-two of 44 walking clones colocalized with cAJ42 or cCMM65 to chromosome 16p13.3. Two clones did not hybridize detectably to chromosome 16 but, instead, localized to chromosome 1q. On the basis of the FISH results, these two clones were most likely mispicks during colony purification. Clones $91.8 \mathrm{~B}$ and 97.10G hybridized to chromosome $16 \mathrm{p} 13.3$ as well as to a more proximal chromosome $16 \mathrm{p}$ locus. Similarly, the overlapping cosmid $2 \mathrm{H} 2$ also localized to the same two loci on chromosome 16. This dual localization is consistent with a chromosome 16 low-copy-number repeat described previously (Germino et al. 1992; European Polycystic Kidney Disease Consortium 1994).

The resulting P1 walking clones were characterized by restriction enzyme analysis and Southern blot hybridization. Size determinations for the 42 P1s from the PKD1 locus were based on summing each clone's EcoRI fragments in the range of $2-48 \mathrm{~kb}$. The clone sizes ranged from 48.4 to $116.8 \mathrm{~kb}$ with a mean of $85.4 \mathrm{~kb}$ and a median of $88.2 \mathrm{~kb}$. The vector component of each P1 clone is $16.8 \mathrm{~kb}$.

Multiple types of information were used to assemble the developing contigs. A NotI restriction map of the D16S125-D16S84 interval physically anchored the cosmids used for the initial walks and provided abundant, spatially defined landmarks to assess the extent of each walk (Germino et al. 1992). Comparisons between the EcoRI fragment patterns of each walking clone and parental clone were used as a qualitative measure of the overlap between clones. $\mathrm{T} 7$ and SP6-derived end probes from walking clones were used as hybridization probes to confirm sequence overlap with the parent clone and to identify which end of the walking clone insert overlapped with the parent clone. Quantitative estimates of overlap and the extent of each walk relied on NotI fragment pattern comparisons. Contig closure was established when the nonoverlapping end of a walking clone hybridized to another developing contig.

The entire D16S125-D16S84 interval could be minimally defined by $12 \mathrm{P} 1$ clones but contained a single gap located between $79.2 \mathrm{~A}$ and $30.1 \mathrm{~F}$. This gap was eliminated with the identification of cosmid $413 \mathrm{C} 12$ by chromosome walking in a gridded cosmid library. The gap in the P1 
A 700-kB Pl CONIIG CONIAINING THE PKDI GENE

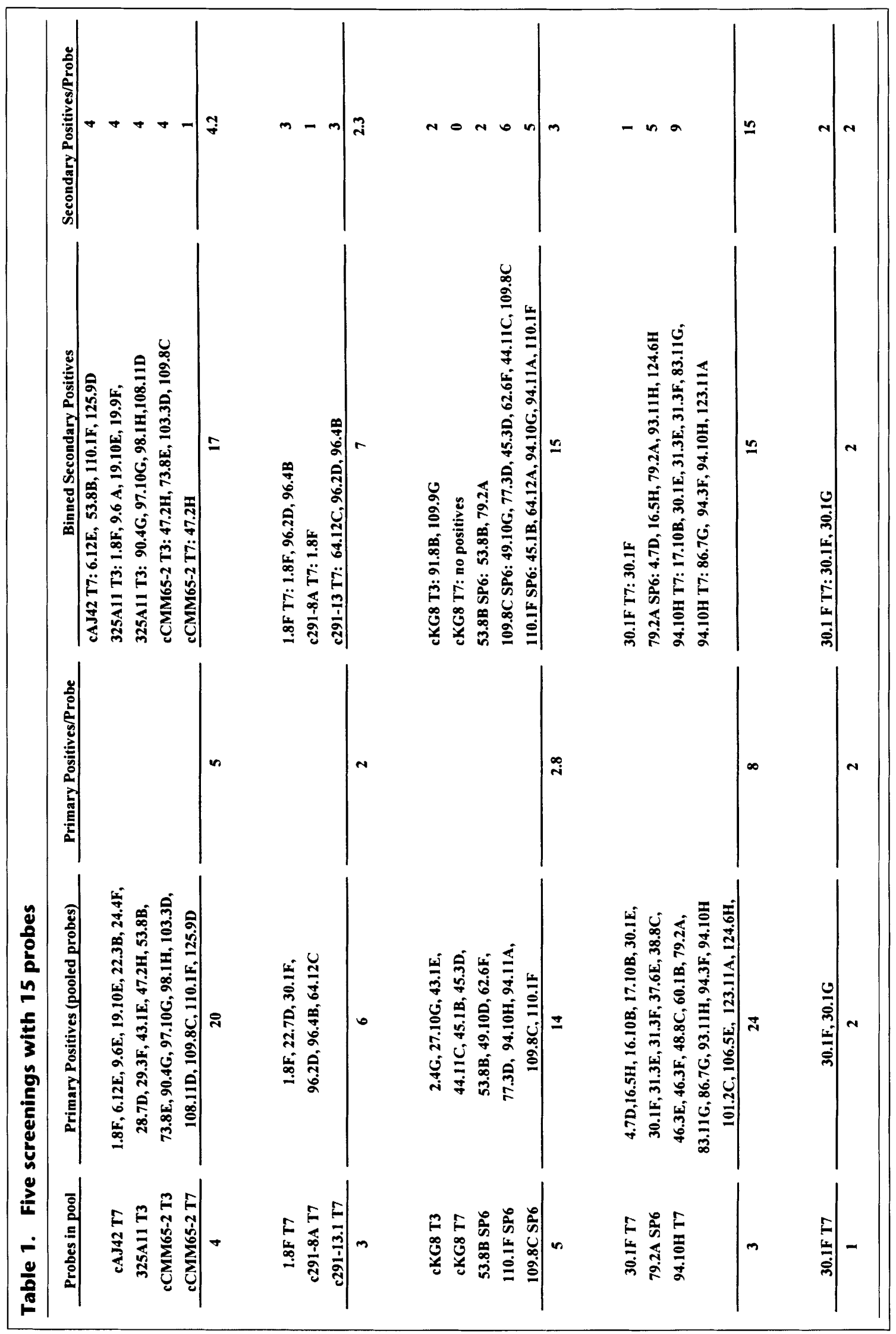




\section{DACKOWSKI ET AL.}

contig was small because end probes from $30.1 \mathrm{~F}$ and 79.2A hybridized to the same 4-kb EcoRI fragment in $413 \mathrm{C} 12$. A previously described cos$\mathrm{mid} / \lambda$ phage contig over the same interval (Germino et al. 1992) contained two small gaps shown in Figure 1. The distal gap in the cosmid $/ \lambda$ phage contig $(-20 \mathrm{~kb})$ is in a similar location as the gap in our P1-only contig. Their proximal gap $(\sim 60 \mathrm{~kb})$ is at least partially contained within the most centromeric P1 of our contig, $94.10 \mathrm{H}$.

\section{DISCUSSION}

We have assembled a set of overlapping cloned genomic reagents to construct a transcriptional map of the minimum genetic interval that encodes PKD1. A 700-kb DNA contig was assembled from a set of 42 unique, chromosome 16-derived P1 clones obtained by screening a three-genome equivalent P1 library (Shepherd et al. 1994) with 15 distinct probes. The D16S125-D16S84 interval could be defined using 12 overlapping P1 clones and 1 cosmid clone. The representation of this interval in the P1 library is consistent with the library's predicted complexity. This observation suggests that this interval's preponderance of repetitive sequences (particularly Alu repeats), genes and associated GC-richness had little impact on clone maintenance during construction of the primary library and the subsequent propagation and distribution of secondary library pools of 10-12 clones per well.

We were unable to recover this segment from the CEPH YAC library using either STS screening (Mark I, Mark II, and Mega-YAC) or locus-specific probes from IRS-PCR screening (Mark II and Mega-YAC). Similar results were described at the Third Chromosome 16 Workshop with only 1 Mega-YAC recovered from the distal 3-Mb portion of chromosome 16p13.3 (Doggett and Callen 1995), which includes the PKD1 locus, whereas the proximal portion of chromosome $16 \mathrm{p} 13.3$ is comprehensively covered. Other reports have described chromosomal regions that also appear to be underrepresented in YAC libraries, including the subtelomeric interval of chromosome Xq28 (Willard et al. 1994), and chromosome 4p (Myers et al. 1994), as well as several regions of chromosome 22 (Scambler 1994).

We have found that the P1 and cosmid clones in this interval of chromosome 16 have a lower frequency of $E c o$ RI sites than expected for the human genome (data not shown). The reduced occurrence of EcoRI sites is consistent with the interval being a member of the human $\mathrm{H} 3$ family, the most GC-rich isochore with an average GC content of 55\% (Saccone et al. 1992). Sample sequencing of the interval including the PKD1 gene (American PKD1 Consortium 1995) and segments revealed by exon trapping (Burn et al., this issue) indicate $>60 \% \mathrm{GC}$ based on $\sim 75 \mathrm{~kb}$ of sequence. The reduced frequency of EcoRI sites could decrease the representation of this region in the CEPH (and other) YAC libraries, because EcoRI partial digestion is used to generate insert DNA for cloning into pYAC4. Compounding the EcoRI effect, is the possibility that the yeast replication machinery, accustomed to a genome of $38.3 \%$ GC, cannot function over sustained intervals of high GC content.

The abundance or particular distribution of repetitive sequences within the interval may also have reduced the likelihood of recovering megaYACs derived from this interval given that mammalian repetitive sequences, particularly the most abundant middle repeats like the Alu class, are believed to facilitate recombination (Green et al. 1991; Schlessinger et al. 1991; Ling et al. 1993; Kouprina et al. 1994; Larionov et al. 1994). As an example of repetitive sequence abundance, we have determined the presence of $\sim 34$ Alu repeats in a 63-kb interval that encompasses the PKD1 gene (American PKD1 Consortium 1995). Twenty-seven of these elements were located in a $30-\mathrm{kb}$ segment. This high Alu density, if maintained throughout the entire $700-\mathrm{kb}$ interval, may have provided the yeast recombinational machinery with a preferred DNA substrate and prevented the formation of stable YACs with the desired sequence integrity. Similar arguments can be extended to include the effects of lowcopy tandem repeats on YAC stability (Neil et al. 1990). The region of chromosome 16 that we analyzed, band $16 \mathrm{p} 13.3$, contains several loci that are duplicated tandemly and may have caused YAC rearrangement or instability. One example includes 26-6DIS (D16S125), which is duplicated at 26-6PROX ( $70 \mathrm{~kb}$ away), and in some individuals a third polymorphic copy exists, $\mathrm{OX}_{\text {dup }}$ (Harris et al. 1994). Another example is described in Burn et al. (this issue), who used exon trapping of the $\mathrm{P} 1$ clones to reveal a pair of $\mathrm{ABC}$ gene family members present in $\mathrm{P} 1 \mathrm{~s} 79.2 \mathrm{~A}$ and $30.1 \mathrm{~F}$.

The P1/cosmid contig described here has two advantages over the previously described cos$\mathrm{mid} / \lambda$ phage contig of the same interval (Germino et al. 1992). First, our predominantly P1 


\section{A 700-kB PI CONTIG CONIAINING THE PKDI GENE}

contig is predicted to be more stable and less prone to rearrangements and deletions than the cosmid/ $\lambda$ phage contig (Kim et al. 1992). This feature is particularly crucial as we begin to sequence the interval. Second, our contig eliminates two small gaps of $\sim 20$ and $\sim 60 \mathrm{~kb}$, which remained in the cosmid/ $\lambda$ phage contig and therefore provides a complete and uninterrupted cloned segment for sequence analysis. Curiously, both gaps in the cosmid/ $\lambda$ phage contig were within regions that are now known to be locally duplicated. The distal gap is near one of two ABClike genes that we identified recently in the interval by exon trapping (Burn et al., this issue). The proximal gap in the cosmid/ $\lambda$ phage contig is within the 26-6DIS/26-6PROX duplication and is substantially covered by the proximal P1 clone in our contig $94.10 \mathrm{H}$.

Defining chromosomal segments with cloned reagents requires the use of multiple library resources. As one of the newer resources available, large insert libraries hosted in $E$. coli have the estimated representation and ease of use to complement the existing approaches to clone specific genomic intervals. Our studies support the estimated $3 \times$ complexity of the P1 library of Shepherd and co-workers (Shepherd et al. 1994) and encourage its use, particularly for cloning regions of known instability or underrepresentation, in YAC libraries. The clones described provide a valuable resource for transcriptional mapping and create a set of sequence-ready templates for a gene-rich interval responsible for at least two inheritable diseases.

\section{METHODS}

\section{Cosmids}

Multiple cosmids were used as reagents to initiate walks in YAC and P1 libraries. Clones 16-166N (D16S277), 16-191N (D16S279), 16-198N (D16S280), and 16-140N (D16S276) were isolated previously from a cosmid library (Lerner et al. 1992). Cosmids cCMM65 (D16S84), c291 (D16S291), cAJ42 (ATP6C), and cKG8 were recovered from total human cosmid libraries (made in-house or by Stratagene, La Jolla, CA) using either a cloned insert (CMM65) or sequence-specific oligonucleotides as probe. The c326 cosmid contig and clone $413 \mathrm{C} 12$ originated from a flowsorted chromosome 16 library (Stallings et al. 1992). The c326 contig was comprised of clones $2 \mathrm{H} 2,77 \mathrm{E} 8,325 \mathrm{~A} 11$, and $325 \mathrm{~B} 10$. All of the cosmids were ordered relative to each other by interphase FISH using three probes and two colors.

\section{YACs}

Primary and secondary pools of the CEPH YAC libraries
(Mark I, Mark II, and Mega-YAC) were screened at Research Genetics (Birmingham, AL) for the presence of STSs derived from the following loci: D16S283, D16\$139, D16S84, and D16S276. STS screening was performed at LANL on primary pools of plates $613-736$ of the CEPH Mark II library and plates 737-984 of the Mega-YAC library for the following loci: D16S291, D16S283, D16S662, D16S663, D16S664, D16S665, D16S666E, D16S1103, and D16S3252. After the TSC2 (European Chromosome 16 Tuberous Sclerosis Consortium 1993) and PKD1 genes (European Polycystic Kidney Disease Consortium 1994) were identified, the LANL primary pools were also screened for the presence of several PKD1 and TSC2 STSs. Primers for STSs were either as described in the Genome Database (GDB, Johns Hopkins University, Baltimore, MD) or selected using the programs OLIGO (National Biosciences, Inc., Plymouth, MN) or ASTS (Rappaport et al. 1994).

Screening of gridded interspersed-repetitive sequence (IRS pools from Mark I, Mark II, and Mega-YAC libraries) with cosmid-specific IRS probes was as described previously (Liu et al. 1995). IRS probes were made from cosmids 16-166N, 16-191N, cAJ42, 16-198N, 325A11, cCMM65, and $16-140 \mathrm{~N}$.

YACs were localized to metaphase chromosomes by FISH. Biotinylated YAC probes were generated by nicktranslating complex mixtures of IRS products from each YAC. Mixtures of sufficient complexity were achieved by performing independent DNA amplifications of total yeast DNA using various Alu primers (Lichter et al. 1990) and then combining the appropriate reactions containing the most diverse products. The hybridization and visualization of the pooled PCR products to standard cytogenetic preparations of short-term cultures of peripheral blood lymphocytes was performed as described previously (Klinger et al. 1992).

\section{Pls}

Chromosome walking experiments were done using a single set of membranes that contained the gridded P1 library pools (Shepherd et al. 1994). The gridded filters were kindly provided by Dr. Mark Leppert and the Technology Access Section of the Utah Center for Human Genome Research at the University of Utah. The P1 gridded membranes were screened using end probes derived from a set of chromosome 16 cosmids (see above) and P1 clones as they were identified. Both RNA transcripts and bubblePCR products were used as end probes. Radiolabeled transcripts were generated using restriction enzyme-digested cosmids or P1s (AluI, HaeIII, RsaI, TaqI) as template for phage RNA polymerases T3, T7, and SP6. The T3 and T7 promoter elements were present on the cosmid-derived templates, whereas T7 and SP6 promoter sequences were contained on the P1-based templates. Transcription reactions were performed as recommended by the manufacturer (Stratagene, La Jolla, CA) in the presence of $\left[\alpha-{ }^{32}\right.$ P]ATP (Amersham Corporation, Arlington Heights, IL). Transcription of P1 templates by SP6 RNA polymerase was less efficient $(-20 \%)$ than T7 RNA polymerasecatalyzed reactions on the same templates. The SP6 RNA polymerase promoter present in the $\mathrm{P} 1$ vector is the native sequence and is known to be less active than the optimized element present in other vectors used for in vitro transcription (Promega, Madison, WI). 


\section{DACKOWSKI ET AL.}

In addition to labeled transcript probes, we also synthesized bubble-PCR products from restriction enzymedigested P1s (AluI, HaeIII, RsaI, TaqI). Bubble adaptors with appropriate overhangs and phosphorylated 5 ' ends were ligated to digested P1 DNA basically as described for YACs (Riley et al. 1990). The sequence of the universal vectorette primer derived from the bubble adaptor sequence was 5 ' GTTCGTACGAGAATCGCT-3' and differed from that of Riley and co-workers with 12 fewer $5^{\prime}$ nucleotides. The $T_{\mathrm{m}}$ of the truncated vectorette primer more closely matched that of the paired amplimer from the vector-derived promoter sequence (SP6, T7). The desired bubble-PCR product was gel purified before radiolabeling (Feinberg and Vogelstein 1983, 1984).

The specificity of all end probes was determined before their use on the single set of gridded P1 filter arrays. Radiolabeled probes were preannealed to Cot1 DNA as recommended (LTI, Gaithersburg, MD) and then hybridized to strips of nylon membrane containing assorted DNAs (see below). Hybridizations were performed in CAK solution $(5 \times$ SSPE, $1 \%$ SDS, $5 \times$ Denhardt's solution, $100 \mathrm{mg} /$ $\mathrm{mL}$ of torula RNA) at $65^{\circ} \mathrm{C}$ overnight. Individual probes were present at a concentration of $5 \times 10^{5} \mathrm{cpm} / \mathrm{ml}$. Hybridized membranes were washed to a final stringency of $0.1 \times \mathrm{SSC} / 0.1 \%$ SDS at $65^{\circ} \mathrm{C}$. The hybridization results were visualized by autoradiography. Membrane-bound DNAs (10-20 ng) included the cloned genomic template used to create the probe, one or more unrelated cloned genomic DNAs, cloned vector (no insert), and human genomic DNA. Probes that hybridized robustly to their cloned template, although not hybridizing to unrelated cloned DNAs, vector DNA, or genomic DNA were used to screen the gridded $\mathrm{P} 1$ filters.

Hybridization to the arrayed P1 pools was performed as described for membrane strips except that multiple probes were used simultaneously, each at the recommended concentration (see above). P1 pools that hybridized to the radiolabeled probe sets were plated at a density of $200-500 \mathrm{CFU} / 100-\mathrm{mm}$ plate (LB plus $25 \mathrm{mg} / \mathrm{ml}$ of $\mathrm{ka}-$ namycin), lifted onto 82-mm HATF membranes (Millipore Corporation, Bedford, MA), processed for hybridization (Sambrook et al. 1989), and screened with the complex probe mixture. A master plate was assembled and consisted of a single positive clone from each P1 pool that was probed. To identify which colony-purified P1s resulted from the various individual probes, multiple P1 DNA dot blots were prepared and each hybridized to individual radiolabeled probes.

The chromosomal origin of each walking clone was determined by two-probe/two-color FISH to metaphase chromosomes. All hybridizations contained a chromosome $16 \mathrm{p} 13.3$ reference probe, for example, cAJ42, as well as a uniquely labeled P1 DNA probe. P1 DNAs were labeled and visualized as described for cosmid-derived probes (Klinger et al. 1992).

Each family of P1 clones derived from individual probes was characterized by restriction enzyme digestion (EcoRI, NotI) and Southern blot hybridization using radiolabeled SP6 and T7 oligonucleotides as probes. Digestion products were resolved electrophoretically by field inversion gel electrophoresis (Carle et al. 1986). Molecular size standards included the 8.3- to 48-kb set of high molecular weight markers (LTI, Gaithersburg, MD), HinDIII-cut $\lambda$ DNA and HaeIII-cut $\phi \times 174$ DNA. The resolving length of the agarose gel was $\sim 20.5 \mathrm{~cm}$, and gels were generally run until the 2027-bp HindIII fragment of $\lambda$ DNA was near the bottom of the gel.

\section{ACKNOWLEDGMENTS}

This work was supported in part by grants from the National Institutes of Health (DK44853 to KWK) and the Department of Energy (W-7405-ENG-36 to NAD). We thank Lynne Goodwin, Judy Tesmer, and Linda Meincke for their YAC screening efforts. We also thank Drs. Tim Burn and Bruce Birren for their helpful comments.

The publication costs of this article were defrayed in part by payment of page charges. This article must therefore be hereby marked "advertisement" in accordance with 18 USC section 1734 solely to indicate this fact.

\section{REFERENCES}

American PDK1 Consortium. 1995. Analysis of the genomic sequence for the autosomal dominant polycystic kidney disease (PKD1) gene predicts the presence of a leucine-rich repeat. Hum. Mol. Genet. 4: $575-582$.

Bellanne-Chantelot, C., B. Lacroix, P. Ougen, A. Billault, S. Beaufils, S. Bertrand, I. Georges, F. Glibert, I. Gros, G. Lucotte, L. Susini, J.-J. Codani, P. Gesnouin, S. Pook, G. Vaysseix, J. Ried, D. Ward, I. Chumakov, D. LePaslier, and D. Cohen. 1992. Mapping the whole human genome by fingerprinting yeast artificial chromosomes. Cell 70: $1059-1068$.

Brook-Carter, P.T., B. Peral, C.J. Ward, P. Thompson, J. Hughes, M.M. Maheshwar, M. Nellist, V. Gamble, P.C. Harris, and J.R. Sampson. 1994. Deletion of the TSC2 and $P K D$ genes associated with severe infantile polycystic kidney disease-a contiguous gene syndrome. Nature Genet. 8: 328-332.

Burn, T.C., T.D. Connors, T.J. Van Raay, W.R. Dackowski, J.M. Millholland, K.W. Klinger, and G.M. Landes. 1996. Generation of a transcriptional map for a 700 kilobase region surrounding the polycystic kidney disease type1 (PKD1) and tuberous sclerosis type 2 (TSC2) disease genes on human chromosome 16p13.3. Genome Res. (this issue).

Carle, G.F., M. Frank, and M.V. Olson. 1986. Electrophoretic separations of large DNA molecules by periodic inversion of the electric field. Science 232: 65-68.

Chromosome 16 Tuberous Sclerosis Consortium. 1993. Identification and characterization of the tuberous sclerosis gene on chromosome 16. Cell 75: 1305-1315.

Chumakov, I.M., P. Rigaut, I. Le Gall, C. Bellanne-Chantelot, A. Billault, S. Guillou, P. Soularue, G. Guasconi, E. Pouilier, I. Gros, M. Belova, J.-L. Sambucy, et al. 1995. A YAC contig map of the human genome. Nature 377: 175-297. 


\section{A 700-kB PI CONTIG CONTAINING THE PKDI GENE}

Doggett, N.A. and D.F. Callen. 1995. Report and abstracts of the third international workshop on human chromosome 16 mapping 1994. Pittsburgh, Pennsylvania, May 7-9, 1994. Cytogenet. Cell Genet. 68: 165-184.

Doggett, N.A., L.A. Goodwin, J.G. Tesmer, L.J. Meincke, D.C. Bruce, L.M. Clark, M.R. Altherr, A.A. Ford, H.-C. Chi, B.L. Marrone, J.L. Longmire, S.A. Lane, et al. 1995. An integrated physical map of human chromosome 16 . Nature (Suppl.) 377: 335-365.

European Polycystic Kidney Consortium. 1994. The polycystic kidney disease 1 gene encodes a $14 \mathrm{~kb}$ transcript and lies within a duplicated region on chromosome 16. Cell 77: 881-894.

Feinberg, A.P. and B. Vogelstein. 1983. A technique for radiolabeling DNA restriction endonuclease fragments to high specific activity. Anal. Biochem. 132: 6-13.

1984. A technique for radiolabeling DNA restriction endonuclease fragments to high specific activity. [Addendum] Anal. Biochem. 137: 266-267.

Gemmill, R.M., I. Chumakov, P. Scott, B. Waggoner, P. Rigault, J. Cypser, Q. Chen, J. Weissenbach, K. Gardiner, H. Wang, Y. Pekaraky, I. Le Gall, et al. 1995. A second-generation YAC contig map of human chromosome 3. Nature (Suppl.) 377: 299-319.

Germino, G.G., D. Weinstat-Saslow, H. Himmelbauer, G.A. Gillespie, S. Somlo, B. Wirth, N. Barton, K.L. Harris, A.M. Frischauf, and S.T. Reeders. 1992. The gene for autosomal dominant polycystic kidney disease lies in a 750-kb CpG-rich region. Genomics 13: 144-151.

Germino, G.G., S. Somlo, D. Weinstat-Saslow, and S.T. Reeders. 1993. Positional cloning approach to the dominant polycystic kidney disease gene, PKD1. Kidney Int. Suppl. 39: \$20-\$25.

Green, E.D., H.C. Riethman, J.E. Dutchik, and M.V. Olson. 1991. Detection and characterization of chimeric yeast artificial-chromosome clones. Genomics 11: $658-669$.

Harris, P.C., N.J. Barton, D.R. Higgs, S.T. Reeders, and A.O. Wilkie. 1990. A long-range restriction map between the alpha-globin complex and a marker closely linked to the polycystic kidney disease 1 (PKD1) locus. Genomics 7: 195-206.

Harris, P.C., S. Thomas, A.B. MacCarthy, R.L. Stallings, M.H. Breuning, D.E. Jenne, T.M. Fink, V.J. Buckle, P.J. Ratcliffe, and C.J. Ward. 1994. A large duplicated area in the polycystic kidney disease 1 (PKD1) region of chromosome 16 is prone to rearrangement. Genomics 23: $321-330$.

Ioannou, P.A., C.T. Amemiya, J. Garnes, P.M. Kroisel, H. Shizuya, C. Chen, M.A. Batzer, and P.J. de-Jong. 1994. A new bacteriophage P1-derived vector for the propagation of large human DNA fragments. Nature Genet. 6: 84-89.
Kim, U.-J., H. Shizuya, P.J. de Jong, B. Birren, and M.I. Simon. 1992. Stable propagation of cosmid sized human DNA inserts in an F factor based vector. Nucleic Acids Res. 20: $1083-1085$.

Klinger, K., G. Landes, D. Shook, R. Harvey, L. Lopez, P. Locke, T. Lerner, R. Osathanondh, B. Leverone, T. Houseal, K. Pavelka, and W. Dackowski. 1992. Rapid detection of chromosome aneuploidies in uncultured amniocytes by using fluorescence in situ hybridization (FISH), Am. J. Hum. Genet. 51: 55-65.

Korenberg, J.R. and M.C. Rykowski. 1988. Human genome organization: Alu, lines, and the molecular structure of metaphase chromosome bands. Cell 53: $391-400$.

Kouprina, N., M. Eldarov, R. Moyzis, M. Resnick, and V. Larionov. 1994. A model system to assess the integrity of mammalian YACs during transformation and propagation in yeast. Genomics 21: 7-17.

Krauter, K., K. Montgomery, S.-J. Yoon, J. LeBlanc-Straceski, B. Renault, I. Marondel, V. Herdman, L. Cupelli, A. Banks, J. Lieman, J. Menninger, P. Bray-Ward, et al. 1995. A second-generation YAC contig map of human chromosome 12. Nature (Suppl.) 377: $321-333$.

Larionov, V., N. Kouprina, N. Nikolaishvili, and M.A. Resnick. 1994. Recombination during transformation as a source of chimeric mammalian artificial chromosomes in yeast (YACs). Nucleic Acids Res. 22: 4154-4162.

Lerner, T., G. Wright, B. Leverone, W. Dackowski, D. Shook, M.A. Anderson, K. Klinger, D. Callen, and G. Landes. 1992. Molecular analysis of human chromosome 16 cosmid clones containing NotI sites. Mamm. Genome 3: $92-100$.

Lichter, P., S.A. Ledbetter, D.H. Ledbetter, and D.C. Ward. 1990. Fluorescence in situ hybridization with Alu and L1 polymerase chain reaction probes for rapid characterization of human chromosomes in hybrid cell lines. Proc. Natl. Acad. Sci. 87: 6634-6638.

Ling, L.L., N.S. Ma, D.R. Smith, D.D. Miller, and D.T. Moir. 1993. Reduced occurrence of chimeric YACs in recombination-deficient hosts. Nucleic Acids Res. 21: $6045-6046$.

Liu, J., V. Stanton Jr., T.M. Fujiwara, J.X. Wang, R. Rezonzew, M.J. Crumley, K. Morgan, P. Gros, D. Housman, and E. Schurr. 1995. Large-scale cloning of human chromosome 2-specific yeast artificial chromosomes (YACs) using an interspersed repetitive sequences (IRS)-PCR approach. Genomics 26: 178-191.

Myers, R.M., R.D. Goold, and G.J. van-Ommen. 1994. Report and abstracts of the Third International Workshop on Human Chromosome 4 Mapping. Palo Alto, California, July 10-11, 1993. Cytogenet. Cell Genet. 66: $218-236$. 


\section{DACKOWSKI ET AL.}

Nagaraja, R., J. Kere, S. MacMillan, M.J. Masisi, D. Johnson, B.J. Molini, G.R. Halley, K. Wein, M. Trusgnich, B. Eble, B. Railey, B.H. Brownstein, et al. 1994. Characterization of four human YAC libraries for clone size, chimerism and $\mathrm{X}$ chromosome sequence representation. Nucleic Acids Res. 22: 3406-3411.

Neil, D.L., A. Villasante, R.B. Fisher, D. Vetrie, B. Cox, and C. Tyler-Smith. 1990. Structural instability of human tandemly repeated DNA sequences cloned in yeast artificial chromosome vectors. Nucleic Acids Res. 18: $1421-1428$.

Okumura, K., J. Menninger, R.L. Stallings, N.A. Doggett, and D.C. Ward. 1994. In situ hybridization mapping of human chromosome 16: Evidence for a high frequency of repetitive DNA sequences. Cytogenet. Cell Genet. 67: $61-67$.

Rappaport, B., J. Gatewood, C. Fields, and N. Doggett. 1994. Software tools for primer site prediction and sequence similarity searches. In Automated DNA sequencing and analysis (ed. D.D. Adams, C. Fields, and J.C. Ventner), pp. 289-293. Academic Press Limited, London, UK.

Riley, J., R. Butler, D. Ogilvie, R. Finniear, D. Jenner, S. Powell, R. Anand, J.C. Smith, and A.F. Markham. 1990. A novel, rapid method for the isolation of terminal sequences from yeast artificial chromosome (YAC) clones. Nucleic Acids Res. 18: 2887-2890.

Saccone, S., A. De-Sario, G. Della-Valle, and G. Bernardi. 1992. The highest gene concentrations in the human genome are in telomeric bands of metaphase chromosomes. Proc. Natl. Acad. Sci. 89: 4913-4917.

Sambrook, J., E.F. Fritsch, and T. Maniatis. 1989. Molecular cloning: A laboratory manual, 2nd ed. Cold Spring Harbor Laboratory Press, Cold Spring Harbor, NY.

Scambler, P.J. 1994. Report and abstracts of the Fourth International Workshop on Human Chromosome 22 Mapping 1994. Cambridge, United Kingdom, July 2-4, 1994. Cytogenet. Cell Genet. 67: 277-294.

Schlessinger, D., R.D. Little, D. Freije, F. Abidi, I. Zucchi, G. Porta, G. Pilia, R. Nagaraja, S.K. Johnson, J.Y. Yoon, A. Srivastava, J. Kere, et al. 1991. Yeast artificial chromosome-based genome mapping: Some lessons from Xq24-q28. Genomics 11: 783-793.

Shepherd, N.S., B.D. Pfrogner, J.N. Coulby, S.L. Ackerman, G. Vaidyanathan, R.H. Sauer, T.C. Balkenhol, and N. Sternberg. 1994. Preparation and screening of an arrayed human genomic library generated with the P1 cloning system. Proc. Natl. Acad. Sci. 91: 2629-2633.

Shimizu, N., S.E. Antonarakis, C. Van Broeckhoven, D. Patterson, K. Gardiner, D. Nizetic, N. Creau, J.-M. Delabar, J. Korenberg, R. Reeves, J. Doeriong, A. Chakravati, et al. 1995. Report and abstracts of the Fifth International Workshop on Human Chromosome 21
Mapping 1994. Tsukuba, Japan, November 9-11, 1994. Cytogenet. Cell Genet. 70: 147-182.

Shizuya, H., B. Birren, U.J. Kim, V. Mancino, T. Slepak, Y. Tachiiri, and M. Simon. 1992. Cloning and stable maintenance of 300-kilobase-pair fragments of human DNA in Escherichia coli using an F-factor-based vector. Proc. Natl. Acad. Sci. 89: 8794-8797.

Stallings, R.L., N.A. Doggett, D. Callen, S. Apostolou, L.Z. Chen, J.K. Nancarrow, S.A. Whitmore, P. Harris, H. Michison, M. Breuning, J.J. Saris, J. Fickett, et al. 1992. Evaluation of a cosmid contig physical map of human chromosome 16. Genomics 13: 1031-1039.

Sternberg, N. 1990. Bacteriophage P1 cloning system for the isolation, amplification, and recovery of DNA fragments as large as 100 kilobase pairs. Proc. Natl. Acad. Sci. 87: 103-107.

Szepetowski, P., D. Perucca-Lostanlen, J. Grosgeorge, D. LePaslier, B.H. Brownstein, G.F. Carle, and P. Gaudray. 1995. Description of a 700-kb yeast artificial chromosome contig containing the BCL1 translocation breakpoint region at $11 \mathrm{q} 13$. Cytogenet. Cell Genet. 69: 101-107.

van-Heyningen, V. and P.F. Little. 1995. Report of the fourth international workshop on human chromosome 11 mapping 1994. Cytogenet. Cell Genet. 69: 127-158.

Wada, M., R.D. Little, F. Abidi, G. Porta, T. Labella, T. Cooper, G. Della-Valle, M. D'Urso, and D. Schlessinger. 1990. Human Xq24-Xq28: Approaches to mapping with yeast artificial chromosomes. Am. J. Hum. Genet. 46: 95-106.

Willard, H.F., F. Cremers, J.L. Mandel, A.P. Monaco, D.L. Nelson, and D. Schlessinger. 1994. Report and abstracts of the Fifth International Workshop on Human X Chromosome Mapping 1994. Heidelberg, Germany, April 24-27, 1994. Cytogenet. Cell Genet. 67: 295-358.

Zuo, J., C. Robbins, P. Taillon-Miller, D.R. Cox, and R.M. Myers. 1992. Cloning of the Huntington disease region in yeast artificial chromosomes. Hum. Mol. Genet. 1: $149-159$.

Received February 21, 1996; accepted in revised form April $24,1996$. 


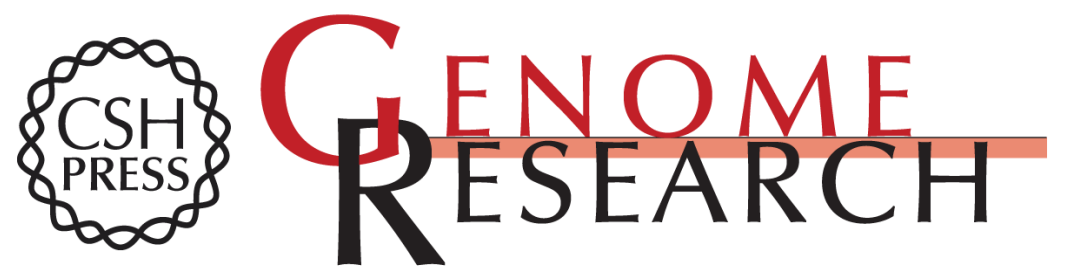

\section{The region surrounding the PKD1 gene: a 700-kb P1 contig from a YAC-deficient interval.}

W R Dackowski, T D Connors, A E Bowe, et al.

Genome Res. 1996 6: 515-524

Access the most recent version at doi:10.1101/gr.6.6.515

References This article cites 46 articles, 6 of which can be accessed free at:

http://genome.cshlp.org/content/6/6/515.full.html\#ref-list-1

\section{License}

Email Alerting Receive free email alerts when new articles cite this article - sign up in the box at the Service top right corner of the article or click here.

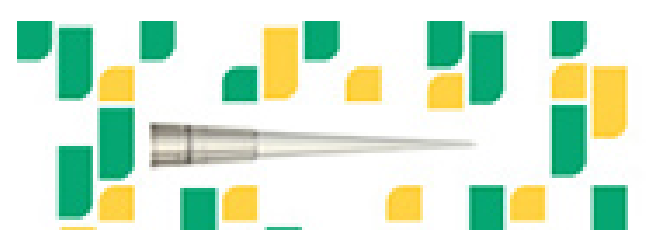

To subscribe to Genome Research go to: https://genome.cshlp.org/subscriptions 